\title{
MENCIPTAKAN KEWARGANEGARAAN EKOLOGIS DI ERA DIGITAL MELALUI KAMPOENG RECYCLE JEMBER
}

\author{
Raudlatul Jannah \\ Program Studi Sosiologi, FISIP Universitas Jember
}

Email: raudlatuljannah.fisip@unej.ac.id

\begin{abstract}
Abstrak
Dalam masyarakat digital, warga negara tidak hanya menggunakan teknologi informasi sebagai alat untuk mendapatkan hiburan namun juga menjadi medium untuk berpartisipasi dalam ruang publik bahkan melakukan upaya pemberdayaan untuk kesejahteraan. Meskipun perkembangan e-commerce sebagai salah satu ciri masyarakat digital telah menimbulkan berbagai dampak negatif seperti konsumerisme, eksploitasi besar-besaran terhadap alam serta masalah sampah elektronik namun era digital juga membuka peluang membangun kesadaran lingkungan melalui konsep kewarganegaraan ekologis. Tulisan ini bertujuan untuk menganalisis upaya membangun kewarganegaraan ekologis melalui gagasan Kampoeng Recycle. Dalam upayanya, Kampoeng Recycle menerapkan beberapa strategi. Pertama, menerapkan trilogi konsep (eco-structures, eco-literacy dan eco-preneurship). Ketiga konsep ini saling berkaitan satu sama lain, meskipun eco-literacy menjadi kunci terpenting membangun kesadaran masyarakat. Kedua, melibatkan generasi muda baik mahasiswa relawan yang ingin terlibat dalam Kampoeng Recycle maupun aktivis GenBI yang aktif mensosialisasikan gagasan Kampoeng Recycle sejak awal. Ketiga, penggunaan media sosial untuk menyebarluaskan jaringan Kampoeng Recycle. Keempat, penggunaan media internet seperti website dan youtube untuk penyebarluasan gagasan. Strategi ini dilakukan dalam upaya membangun kesadaran, etika dan moral warga negara terhadap lingkungannya khususnya terkait masalah sampah. Harapannya adalah terwujudnya perilaku bertanggungjawab dalam mengelola dan melestarikan lingkungan pada setiap warga negara.
\end{abstract}

Kata Kunci : Kewarganegaraan Ekologis, Masyarakat Digital, Kampoeng Recycle

\begin{abstract}
In the digital society, citizens not only use the information technology to get entertainment but also to participate in a public sphere in order to empower society. Although the development of e-commerce has led to a variety of negative impacts such as consumerism, massive exploitation of nature as well as the problem of electronic waste but the digital age has also opened opportunities in building environmental awareness. This paper aims to analyze the strategy of creating the ecological citizenship in digital era through the idea of Kampoeng Recycle. Dealing with these aims, Kampoeng Recycle applies some strategies. First, apply the trilogy concept (eco-structures, eco-literacy, and eco-preneurship). These three concepts are inter-related to each other, although eco-literacy became the most important key to build community awareness. Second, involving the young generation both student volunteers who want to get involved in your Recycle or GenBI activist who actively promotes the idea of Kampoeng Recycle from the beginning. Third, apply social media and Internet to expand the network of Kampoeng Recycle. Fourth, apply internet media such as websites and YouTube to disseminate the ideas. Having this strategy, member of Kampoeng Recycle believe that the hope of creating ecological citizenship in Jember district will be realized.
\end{abstract}

Key Word : Social Capital, Women's Groups, Disaster, Capacity, Woolcock. 


\section{LATAR BELAKANG}

Era digital adalah penanda peradaban manusia hari ini. Sebuah era dimana kebudayaan manusia berada dalam "bentuk yang baru", Levin (2014) bahkan menyebutkan bahwa era digital merupakan era yang ditandai dengan beberapa simptoms, antara lain kekaburan antara yang riil dan yang virtual; kekaburan antara manusia, mesin-mesin dan alam; dan pembalikan dari yang semula kekurangan informasi menjadi berkelimpahan informasi. Era ini juga ditandai oleh tiga aspek penting pembentuk kebudayaan manusia yaitu media sosial (social media) sebagai salah satu cara membentuk kesadaran sosial (social consciousness); identitas personal secara online (personal identity online) menjadi pembentuk kepribadian dan Data Intensive Science sebagai metode baru dalam paradigma ilmu pengetahuan. Kenyataan ini di satu sisi memberi peluang bagi umat manusia meski di sisi lain kita tidak bisa menutup mata pada kecenderungan kecenderungan negatif yang menyertainya.

Perkembangan teknologi dari teknologi mekanik/ analog menuju teknologi digital sejak sekitar 1980 dan internet sejak awal tahun 1990an telah menciptakan era digital. Sejak dikembangkannya personal komputer dengan teknologi microprocessor telah menciptakan revolusi teknologi yang sangat pesat. Kemudian semakin meluas tidak hanya dalam bentuk personal komputer namun juga ponsel. Teknologi ini, yang kemudian disebut sebagai teknologi informasi dan komunikasi (ICTs/information communication technologies) atau teknologi cyber atau lebih dikenal sebagai teknologi digital atau media digital baru. Teknologi ini telah menyentuh seluruh dimensi keseharian manusia, mempengaruhi interaksi dalam keluarga, hiburan, ragam pekerjaan, pendidikan, ekonomi dan relasi yang dipresentasikan dan dikonsumsi melalui media (Lupton, 2013).
Bahkan Castells (1998) kemudian menyimpulkan bahwa perkembangan teknologi ini telah mendorong perubahan masyarakat secara fundamental.

Lebih detail Yahya (2018) menyebutkan era industri 4.0 adalah era distrupsi teknologi dimana terjadi sebuah bidang akan membuat pergerakan dunia industri dan persaingan kerja menjadi tidak linear. Mengutip Hermann (2016) Yahya juga menyebutkan bahwa ada empat desain prinsip industri 4.0. Pertama, interkoneksi (sambungan) yaitu kemampuan mesin, perangkat, sensor, dan orang untuk terhubung dan berkomunikasi satu sama lain melalui Internet of Things (IoT) atau Internet of People (IoP). Kedua, transparansi informasi merupakan kemampuan sistem informasi untuk menciptakan salinan virtual dunia fisik dengan memperkaya model digital dengan data sensor termasuk analisis data dan penyediaan informasi. Ketiga, bantuan teknis berupa kemampuan sistem bantuan untuk mendukung manusia. Dan terakhir Keempat, keputusan terdesentralisasi yang merupakan kemampuan sistem fisik maya untuk membuat keputusan sendiri dan menjalankan tugas seefektif mungkin. Prinsip industri 4.0 inilah yang mendorong perkembangan e-commerce yang merupakan mesin penggerak pertumbuhan ekonomi di era millenium baru ini (Sui and Rejeski, 2002). Sayangnya pertumbuhan ekonomi yang pesat seringkali tidak diiringi dengan kesadaran lingkungan pelakunya sehingga yang terjadi adalah semakin pesat pertumbuhan ekonomi maka semakin besar dampak kerusakan lingkungan yang mungkin terjadi.

Heckeu et al (2006) (dalam Yahya, 2018) menyebutkan bahwa tantangan industri 4.0 salah satunya adalah tantangan berupa perubahan iklim dan kelangkaan sumber daya. Hal ini sangat bergantung pada pola pikir berkelanjutan, penguatan motivasi menjaga lingkungan dan mengembangkan kreativitas untuk solusi keberlanjutan yang baru. Sementara itu jika merujuk pada undang-undang nomor 23 
tahun 1997 tentang pengelolaan lingkungan hidup pasal 5 ayat 3 yang menyatakan bahwa setiap orang mempunyai hak untuk berperan dalam rangka pengelolaan lingkungan hidup. Hal ini menunjukkan bahwa pada era ini setiap warga negara memiliki tantangan untuk berperan dalam mengelola dan melestarikan lingkungan hidupnya.

Sebagai negara berkembang Indonesia juga tidak lepas dari krisis lingkungan seperti masalah polusi air, polusi udara, illegal logging, kebakaran hutan, kelangkaan air, kerusakan tanah dan masalah sampah. Sayangnya beberapa hasil riset menyebutkan bahwa krisis ekologi yang dialami oleh Indonesia sebagai akibat dari kurangnya kesadaran lingkungan di kalangan warga negara (Prasetiyo dkk, 2016). Oleh karena itu krisis ekologis sudah seharusnya menjadi perhatian semua warga negara.

\section{MASYARAKAT DIGITAL : E-COMMERCE, KONSUMERISME DAN MASALAH SAMPAH}

E-commerce atau electronic commerce yaitu kumpulan teknologi, aplikasi dan bisnis yang menghubungakan perusahaan atau perseorangan sebagai konsumen untuk melakukan transaksi elektronik, pertukaran barang dan pertukaran informasi melalui internet atau informasi. Fenomena ini ditandai dengan menjamurnya toko-toko online dan transaksi elektronik antara pedagang dan pembeli yang umumnya hanya bertemu secara online. Selain itu, E-merging digital economy adalah bukti keberhasilan terbesar internet basedbusinesses (Sui and Rejeski, 2002). Saat ini pengguna internet di Indonesia sepanjang data tahun 2017 menurut laporan Asosiasi Penyelenggara Jasa Internet Indonesia (APJII) sebesar 143 juta orang dari total 262 juta penduduk Indonesia. 72,41\% adalah masyarakat urban yang tidak hanya menggunakan internet untuk berkomunikasi tetapi juga untuk membeli dan menjual barang dan jasa.

Sejak e-commerce dilepaskan ke publik beberapa ahli menyebutkan kelebihan internet based-businesses terhadap lingkungan di antaranya adalah mengurangi penggunaan kertas (paperless). Hal ini dibuktikan dengan pengurangan penggunaan kertas untuk membuat brosur atau catalog maupun majalah untuk promosi. Bahkan banyak ahli di U.S. yang menyebut bahwa kehadiran e-commerce dan teknologi informasi telah secara signifikan mengurangi masalah sampah di perkotaan dan bahkan meningkatkan praktek pengelolan sampah berbasis reuse dan recycle pada produk yang dijual secara global (Sui and Rejeski, 2002).

Meskipun demikian setidaknya terdapat tiga kelemahan e-commerce yang haruslah dikaji lebih dalam khususnya terkait dengan dampak terhadap lingkungan. Pertama, sisi negatif dari keberadaan e-commerce ini adalah perilaku konsumerisme masyarakat khususnya pengguna internet yang umumnya masih muda. Meningkatnya konsumsi masyarakat bisa berarti meningkatnya sampah baik dari pengemasan produk itu sendiri maupun dari perilaku membeli yang tidak didasarkan kebutuhan (konsumtif). Perilaku konsumtif ini terjadi sebagai akibat kemudahan teknologi atau aplikasi serta promosi yang dapat dilakukan melalui internet secara terus menerus, setiap saat dan menjangkau seluruh pengguna smartphone yang kebanyakan adalah anak muda. Masyarakat digital yang juga ditandai dengan keberlimpahan informasi memudahkan konsumen untuk memilih produk yang akan dibeli tanpa dibatasi oleh wilayah. Demikian juga dengan informasi mengenai harga dan promosi yang sangat bersaing diantara toko-toko online. Hal ini dengan sendirinya mendorong pembeli untuk dengan mudah melakukan transaksi jual beli secara online. 


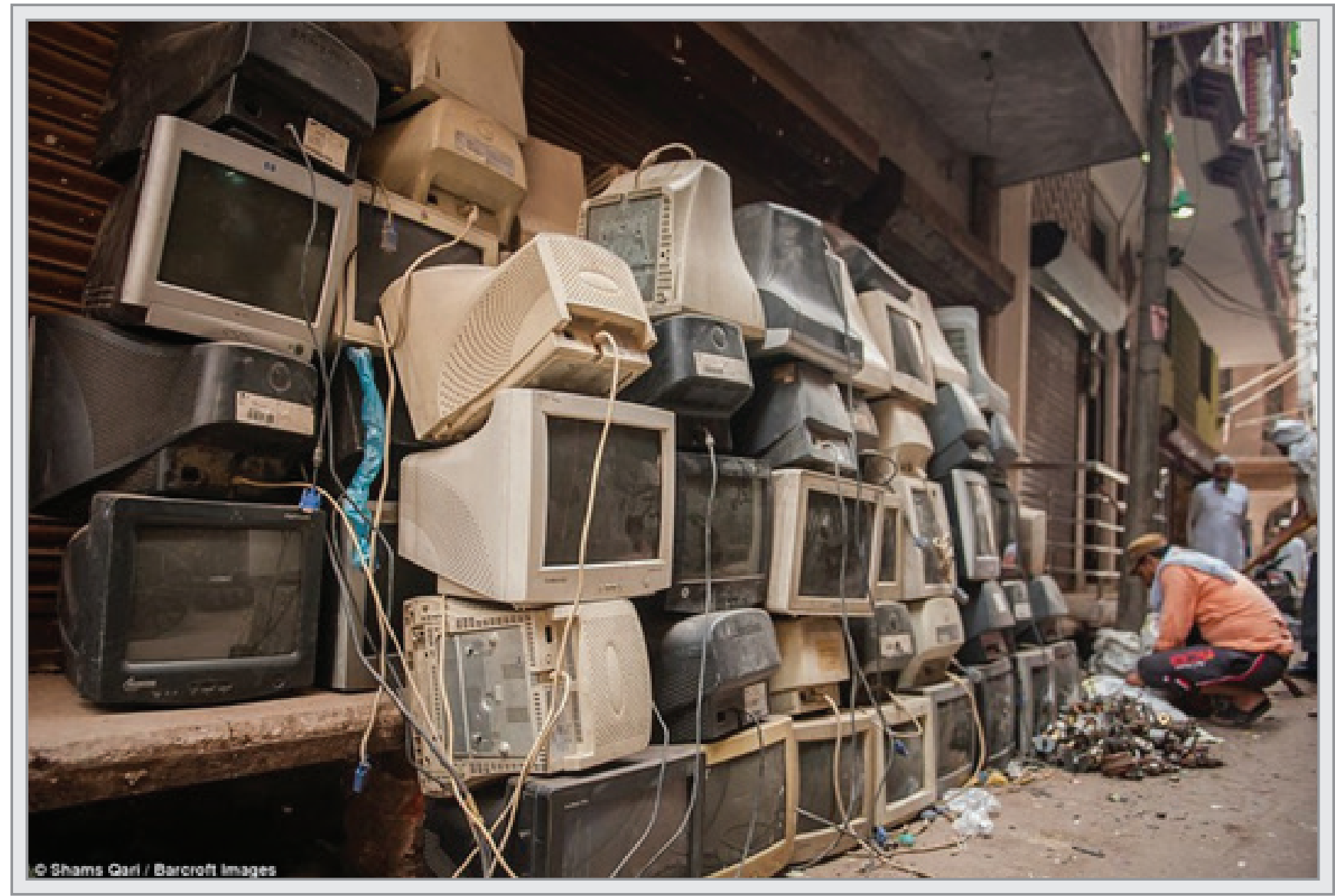

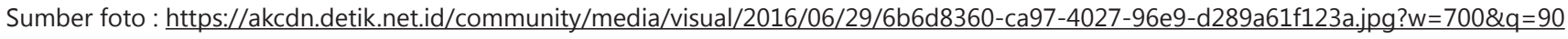

Kedua, Kenyataan yang kemudian dihadapi oleh masyarakat adalah permasalahan sampah. Seiring dengan pesatnya kemajuan bisnis e-commerce dan teknologi informasi maka kebutuhan akan alat elektronik berupa laptop, ponsel dan tablet pendukung e-commerce juga meningkat tajam. Hal ini pada akhirnya menyebabkan tumpukan sampah elektronik (e-waste) yang luar biasa. Bahkan (dalam https://akcdn.detik.net.id/) disebutkan bahwa Asia menjadi benua penyumbang sampah elektronik terbesar, dengan pertumbuhan mencapai $63 \%$ dalam lima tahun (2010-2015). Selain itu, Berdasarkan penelitian dari United Nations University, untuk skala global, pada 2018 mendatang diperkirakan jumlah sampah elektronik akan terus bertambah mencapai 49,8 juta ton, dengan tingkat pertumbuhan 4\%-5\% pertahunnya.

Ketiga, sementara itu dalam hal konsumsi energi, masyarakat digital menjadi masyarakat yang sangat boros energi. Sebagai bagian dari budaya digital yang serba cepat dan nyaman, penggunaan energi untuk jasa transportasi yang digunakan untuk mengantar barang yang dibeli melalui e-commerce telah meningkatkan konsumsi bahan bakar perusahaan logistik. Era digital telah menciptakan tuntutan atas kecepatan, termasuk kecepatan ketersediaan barang. Hal ini kemudian memaksa perusahaan ekspedisi/logistik untuk segera mengantar barang pelanggan secepat mungkin, meski dengan truck yang setengah kosong (half empty) (Sui and Rejeski, 2002).

Berdasarkan laporan riset yang dirilis Savills Plc (dalam https://ekbis.sindonews.com) industri logistik tumbuh berkat kinerja sektor konsumsi, sejalan dengan pertumbuhan penduduk Indonesia yang pada tahun 2020 diperkirakan akan mencapai 270 juta. Dibandingkan tahun 2010, tingkat pengeluaran konsumsi meningkat 1,42 kali 
menjadi Rp1,309 triliun. Kehadiran perusahaan logistik sangat membantu perkembangan e-commerce. Perusahaan logistik bahkan menyediakan layanan penanganan logistik untuk e-commerce, mulai dari pergudangan, distribusi, sampai foto produk. Beberapa perusahaan logistik yang cukup dikenal antara lain Wahana Logistik, Pandu Logistik, Republic Express (RPX), Cahaya Logistik, Synergy First Logistik, PT Pos Indonesia, dan Citra Van Titipan Kilat (TIKI) dan PT Tiki Jalur Nugraha Ekakurir (JNE).

Keempat, penggunaan energi untuk komputer yang digunakan untuk mendukung industri juga meningkatkan konsumsi energi. Dalam (http://www.listrikindonesia.com) disebutkan bahwa pengguna energi terbesar di Indonesia adalah sektor industri dengan pertumbuhan 39,6\% di tahun 1990 menjadi 51,86\% pada tahun 2009, atau lebih dari setengah penggunaan total energi nasional. Pengguna terbesar berikutnya adalah sektor transportasi dengan 30,77\%, diikuti dengan sektor rumah tangga sebesar $13,08 \%$ dan sektor komersial sebanyak 4,28. Penggunaan energi yang semakin meningkat menjadi bukti bahwa pertumbuhan ekonomi yang dimediasi oleh teknologi digital memberikan dampak terhadap lingkungan, khususnya dalam eksploitasi besarbesaran terhadap alam.

\section{PELUANG MEMBANGUN KEWARGANEGARAAN EKOLOGIS DI ERA DIGITAL}

Fenomena e-commerce sebagai bagian dari masyarakat digital menjadi pedang bermata dua bagi perkembangan peradaban manusia. Di satu sisi pertumbuhan ekonomi diharapkan meningkatkan kesejahteraan masyarakat, namun di sisi lain, pertumbuhan ekonomi di era digital juga menyebabkan peningkatan konsumsi masyarakat yang memicu eksploitasi terhadap alam. Pada akhirnya upaya peningkatan kesadaran masyarakat atas lingkungan menjadi harapan dan tantangan bagi keberlanjutan masyarakat digital.

Era digital tidak hanya ditandai dengan globalisasi di segala bidang tapi nampaknya juga telah membawa kita pada akibat-akibat secara global. Degradasi lingkungan dan kerusakan alam yang dialami oleh manusia tidak berbatas teritori (Nagra, 2010). Gagasan pembentukan ecological citizenship (kewarganegaraan ekologis) sangat penting untuk mengembalikan tanggung-jawab warga negara terhadap ekologinya. Kewarganegaraan ekologis hakikatnya juga meliputi pemahaman tentang isu-isu ekologi, hak-hak, tanggung jawab warga negara dalam isu lingkungan hidup. Tidak hanya itu, kewarganegaraan ekologis juga mencakup upaya untuk mengatasi masalah lingkungan sekaligus untuk mempromosikan interaksi manusia yang positif dan berkelanjutan dengan lingkungan sekitar (Clarke \& Agyeman, 2011:1775; Latta, 2007:18). Jika dikaitkan dengan konteks warga negara di era digital, dimana media sosial menjadi media untuk membuat perubahan dan pemberdayaan masyarakat (Lupton, 2013), maka peluang membangun kewarganegaraan ekologis akan semakin terbuka.

Konsep kewarganegaraaan ekologis (ecological citizenship) ialah pemikiran yang berkaitan erat dengan tata cara etika dan moral warga negara terhadap lingkungannya. Hal ini terwujud dari perilaku bertanggungjawab dalam mengelola dan melestarikan lingkungan. Meski dibangun dari filsafat politik hijau, konsep kewarganegaraan ekologis kemudian mengalami pendalaman dan perluasan. Latta dan Garside (2005) menyebutkan beberapa ilmuwan yang mengembangkan konsep kewarganegaraan ekologis memiliki kekhususannya masing-masing, (Dobson dan Bell 2006; Dobson dan Valencia Sáiz 2005) melihat pada aspek perubahan sikap; (Curtin 1999; Smith 1998; Smith 2005) menekankan pada aspek etika lingkungan; 
(Carlsson dan Bruun Jensen 2006; Gough dan Scott 2006) menitik-tekankan kewarganegaraan ekologis dalam aspek pendidikan; (MacGregor, 2006) pada aspek gender; (Valencia Sáiz 2005; Dobson 2003; Jelin 2000) juga menekankan pada aspek skala politik ekologis yang tepat - dari lokal sampai global; (Bell 2005; Hailwood 2005; Eckersley 1996) menekankan pada hak dan kewajiban; partisipasi, dan karakter demokrasi (Barry 2006, 2002, 1999; Christoff 1996); (Agyeman and Evans 2006; Dobson 2003) pada aspek keterkaitan antara keadilan sosial dan kesehatan lingkungan. Dan (Barry 2002, 1999; Dobson 2003) menjelaskan mengenai hubungan antara ruang privat dan ruang publik dalam tindakan kewarganegaraan ekologis.

Terkait dengan konsep warganegara ekologis di era digital, hal ini sejalan dengan konsep warga negara digital (digital citizenship) dimana penggunaan teknologi digital oleh warga negara sebagai medium untuk mengakses informasi dan berpartisipasi dalam kegiatan-kegiatan publik baik yang berkaitan dengan akses sumber-sumber ekonomi, partisipasi politik dan bahkan kampanye gerakan pro lingkungan. Untuk itu warga negara di era digital perlu dibekali dengan kemampuan dan skill untuk berpartisipasi di dunia digital (Mossberger et al, 2008).

Ada beberapa alasan mengapa warganegara digital perlu dibekali dengan keterampilan, Mossberger et al, merangkum setidaknya dalam tiga alasan. Pertama, umumnya warganegara digital adalah anak muda. Sebagai dunia baru, budaya digital belum memiliki norma yang jelas. Oleh karena itu para warga digital haruslah belajar tentang cara menjadi warganegara yang baik dan bertanggung jawab sehingga dapat menciptakan kebaikan dan berpartisipasi dalam ruang publik digital. Kedua, perlu dipahami bahwa dunia digital memiliki risiko. Warga negara digital bisa mengurangi risiko dengan mengetahui hak dan kewajiban warganegara. Ketiga, menjadi sebuah keharusan bagi warga negara digital untuk melek digital dan sekaligus memperhatikan etika digital.

Dalam upaya membangun kewarganegaraan ekologis, era digital telah menciptakan beberapa peluang. Pertama, warga negara digital yang umumnya adalah anak muda, merupakan warga negara yang sangat potensial untuk mengembangkan kesadaran lingkungan. Sebagai generasi muda, umumnya warga negara digital masih memiliki idealisme dan rasa ingin tahu mengenai apa yang terjadi di sekitar kita. Hal ini terlihat dari beritaberita yang tiba-tiba viral dan menyita perhatian banyak netizen. Dengan semakin banyaknya website dan media sosial yang menampilkan isu lingkungan, dengan sendirinya akan semakin banyak wacana tentang lingkungan yang diterima oleh warga negara digital. Hal ini membuka peluang untuk mengkampanyekan gerakan peduli lingkungan. Strategi ini juga yang digunakan oleh gerakan Kampoeng Recycle Jember.

Kedua, era digital yang ditandai dengan norma yang belum jelas bisa saja melahirkan risiko, namun kita tidak dapat mengesampingkan peluang yang mungkin bisa dimanfaatkan dalam penyebarluasan gagasan kewarganegaraan ekologis. Dimana masyarakat digital tidak hanya menggunakan media digital hanya sebatas hiburan namun juga digunakan dalam aktivitas sebagai warga negara. Memberikan opini di media sosial terkait isu-isu lingkungan, mengisi petisi untuk lingkungan atau bahkan menghimpun donasi untuk konservasi lingkungan dapat menjadi aktivitas warga negara yang sangat penting bagi lingkungan.

Ketiga, seperti halnya warganegara digital yang perlu meningkatkan skill sehingga dapat melek digital dan mempraktekkan etika digital, kewarganegaraan ekologis juga mensyaratkan etika lingkungan dan ecoliteracy. Hal ini dikuatkan oleh Mariyani, (2017) dimana membangun kesadaran kewarganegaraan ekologis hal ini dilakukan dengan 
tiga cara yakni guru melek ekologi, ecoliteracy dan komunitas yang mau peduli lingkungan.

\section{MEMBANGUN KEWARGANEGARAAN EKOLOGIS DALAM MASYARAKAT DIGITAL MELALUI KAMPOENG RECYCLE JEMBER}

\subsection{Sejarah Kampoeng Recycle}

Bermula dari terbentuknya Bank Sampah Sahabat Ibu, ibu-ibu PKK RT 6 akhirnya berinisiatif untuk memperluas gagasan menjadikan lingkungan mereka menjadi kampung yang mampu mengolah sampah mereka sendiri. Akhirnya lahirlah "Kampoeng Recycle". Bersama dengan kelompok anak muda GenBI yang merupakan penerima beasiswa BI dan rumah literasi Indonesia yang aktif menggalakkan kegiatan literasi. Pada bulan Desember 2017 diresmikanlah ide membangun lingkungan yang fokus pada pengelolaan sampah.
Di awal-awal sosialisasi untuk mengumpulkan sampah, banyak masyarakat RT 6 RW 40 Perumahan Taman Gading Kabupaten Jember yang enggan mengumpulkan sampah. Semula ibu-ibu pesimis rencana untuk membangun Bank Sampah akan berhasil, namun seiring waktu, upaya sosialisasi yang mereka lakukan ternyata membuahkan hasil. Perubahan mindset yang cukup penting adalah dari konsep buanglah sampah menjadi simpanlah sampah. Padahal Sampah itu sendiri adalah buangan yang dihasilkan dari aktivitas manusia dan hewan yang berupa padatan yang dibuang karena sudah tidak berguna atau diperlukan lagi, (Tchobanogious et al, 1993). Atau definisi yang lain, sampah adalah sisa aktivitas manusia yang sudah tidak digunakan dan tidak diinginkan lagi. Hal ini tentu bisa menjelaskan bagaimana sulitnya meyakinkan para ibu-ibu untuk harus menyimpan apa yang tidak lagi dibutuhkan dan diinginkan.

Sampai pada akhirnya ibu-ibu RW 40 menyadari bahwa sampah kering mereka seperti kertas bekas, bungkus minyak goreng, botol sirup, botol, kardus
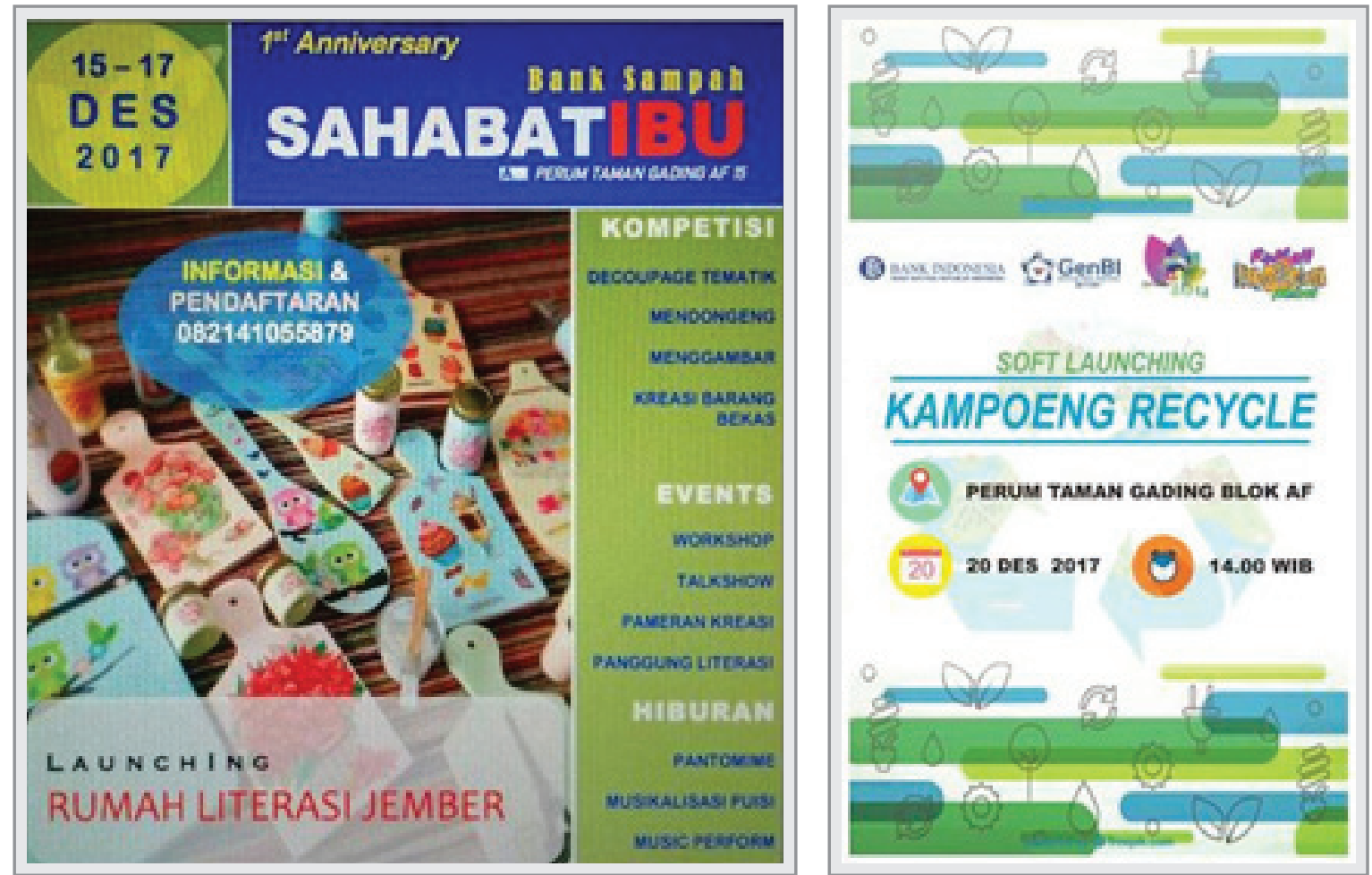

Sumber : Nurul Hidayat (Grup wa Kedai Imaji) 
dan gelas air mineral bernilai jual. Misalnya per kilogram bungkus plastik dihargai Rp 500, kertas HVS Rp 1.500, kertas koran Rp 2.000, kardus Rp 1.500, wadah plastik Rp 2.500, hingga besi tua mulai dari Rp 4.000. Dengan pengelolaan dari pengurus Bank Sampah Sahabat Ibu, ibu-ibu bisa menabung uang dari penjualan sampah, hingga sewaktu-waktu mereka membutuhkan duit, mereka bisa memintanya ke pengurus. Langkah awal inilah yang membuat mereka bersemangat mengembangkan Kampoeng Recycle.

\subsection{Strategi Kampoeng Recycle Dalam}

\section{Membangun Kewarganegaraan Ekologis}

Salah satu pendiri Kampoeng Recycle, Nurul Hidayat percaya bahwa dengan konsep yang matang dan saling terhubung maka gagasan Kampoeng Recycle akan terwujud dengan utuh. Terdapat beberapa strategi gerakan yang digunakan oleh pengurus Kampoeng Recycle dalam mewujudkan kewarganegaraan ekologis.

\section{Membangun Trilogi Kampoeng Recycle}

Gagasan Kampoeng Recycle ini dibangun dari tiga konsep penting yakni eco-structures, eco-literacy dan eco-preneurship. Gagasan Eco Structures diwujudkan dalam struktur fisik yang ramah lingkungan dan menggunakan bahan-bahan yang dihasilkan dari recycle. Misalnya terdiri atas taman recycle, tempat sampah 3R, green corridor, taman toga, pondok kreasi, dan selfie corner. Sedangkan Eco Literacy, diwujudkan dalam mengembangkan taman baca, mendirikan green school serta kegiatan-kegiatan sosialisasi di ruang publik baik di sekolah-sekolah maupun di ruang publik seperti kampanye yang dilakukan oleh Kampoeng Recycle pada kegiatan CFR di alun-alun Jember.

Eco literacy ini menjadi bagian kunci, dimana kesadaran lingkungan menjadi penggerak perubahan itu sendiri. Dengan adanya pengetahuan tentang hak dan kewajiban warga negara terhadap lingkungan, perubahan sikap terhadap lingkungan dapat terjadi. Salah satu sekolah yang tertarik dengan konsep Kampoeng Recycle adalah SMAK Santo Paulus di Kabupaten Jember. Pada akhir bulan Juli 2018, Kampoeng Recycle bersama Generasi Baru Indonesia (GenBI) Jember melakukan pertisipasi pendampingan dan launching Bank Sampah. Hal ini dilakukan selain untuk meningkatkan kepedulian para pelajar di SMAK Santo Paulus terhadap sampah juga untuk melatih kepedulian lingkungan mereka dengan menjadi nasabah Bank Sampah Kampoeng Recycle Jember.

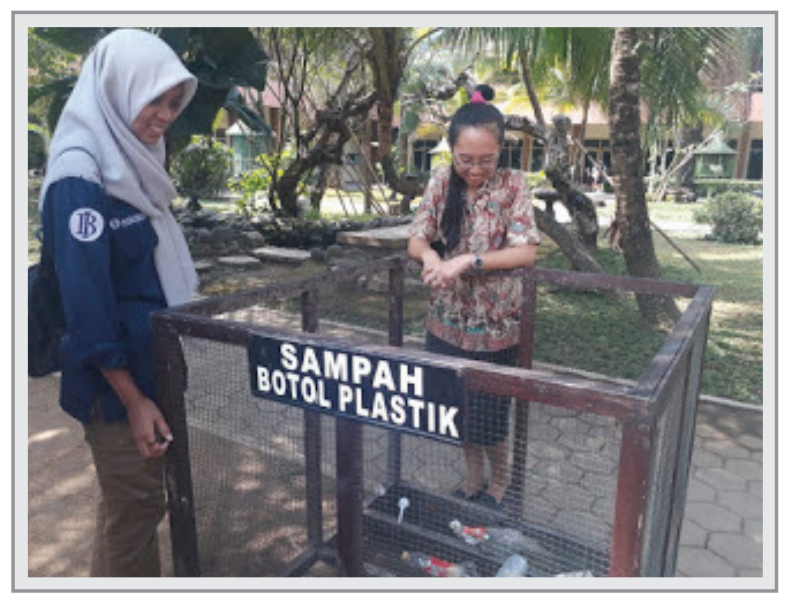

Sumber : (http://kampoengrecycle.blogspot.com/2018/08/ mengenal-kampoeng-recycle-jember-what.html)

Selanjutnya, konsep Eco-Preneurship, dilakukan melalui kegiatan bank sampah dan kreasi daur ulang barang melalui decoupage. Selain itu, tanaman hidroponik dan tanaman toga yang ditanam di lingkungan sekitar memberikan keuntungan bagi warga setempat.

\section{Pelibatan Generasi Muda}

Masyarakat digital, ditandai dengan anak muda. Seperti Kampoeng Recycle yang lahir dari inisiatif anak muda. Terdorong oleh kesadaran masyarakat terhadap pengelolaan sampah yang masih belum optimal, pengurus RT 6 dan ibu-ibu PKK serta mahasiswa dan GenBI akhirnya melahirkan Kampoeng Recycle. 


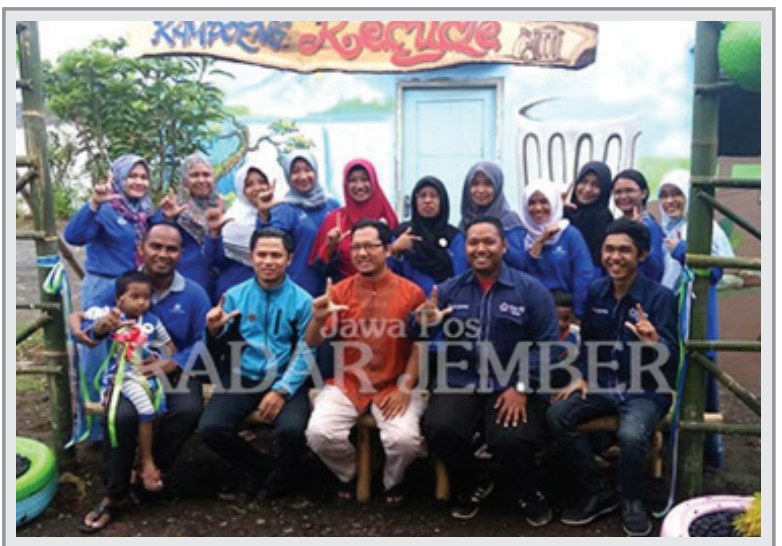

Sumber foto : Pengurus Kampoeng Recycle. (https://radarjember.jawapos.com/read/2017/12/27/35837)

Upaya untuk merekrut semakin banyak anak muda untuk tergabung dalam gerakan Kampoeng Recycle ini terlihat dari jargon yang mereka gunakan yakni "Sampah Aja Diperhatiin, Apalagi Kamuиu......”. Dalam perjalanannya jargon ini menjadi begitu populer, menunjukkan bahwa para aktivis Gerakan Kampoeng Recycle ini adalah individu yang sangat perhatian pada sesama. Jargon ini membentuk kepribadian pada diri pelaku gerakan.

Sebagai sebuah gerakan masyarakat yang diinisiasi oleh pemuda, maka salah satu kunci kesuksesan gerakan ini adalah dengan merekrut sebanyak mungkin relawan yang secara sukacita terlibat dengan kapasitasnya masing-masing. Maka dengan semangat kebersamaan, Kampoeng Recycle juga berjejaring dengan semua pihak, baik pemerintah (DLH, Dinas Pendidikan, Dinas Perekonomian), swasta (seperti pengusaha, korporasi, Lembaga Swadaya) dan anggota masyarakat lainnya baik secara individual maupun kelompok.

\section{Penggunaan Media Sosial (Whatsapp, Instagram, Facebook) Untuk Membangun Jaringan}

Dalam masyarakat digital, realitas dan virtualitas menjadi pembentuk kebudayaan itu sendiri.
Pada masyarakat digital bahkan, eksistensi warga negara tidak hanya ditentukan di dunia nyata, namun juga sangat bergantung pada dunia maya (virtual reality). Semua fenomena yang terjadi di dunia nyata, tidak jadi nyata jika tidak tampil dalam dunia maya. Demikian juga dengan gerakan Kampoeng Recycle tidak akan nyata jika tidak menjadi fenomena di dunia maya. Hal ini menunjukkan bahwa media sosial telah memiliki peran yang signifikan dalam kehidupan sehari-hari.

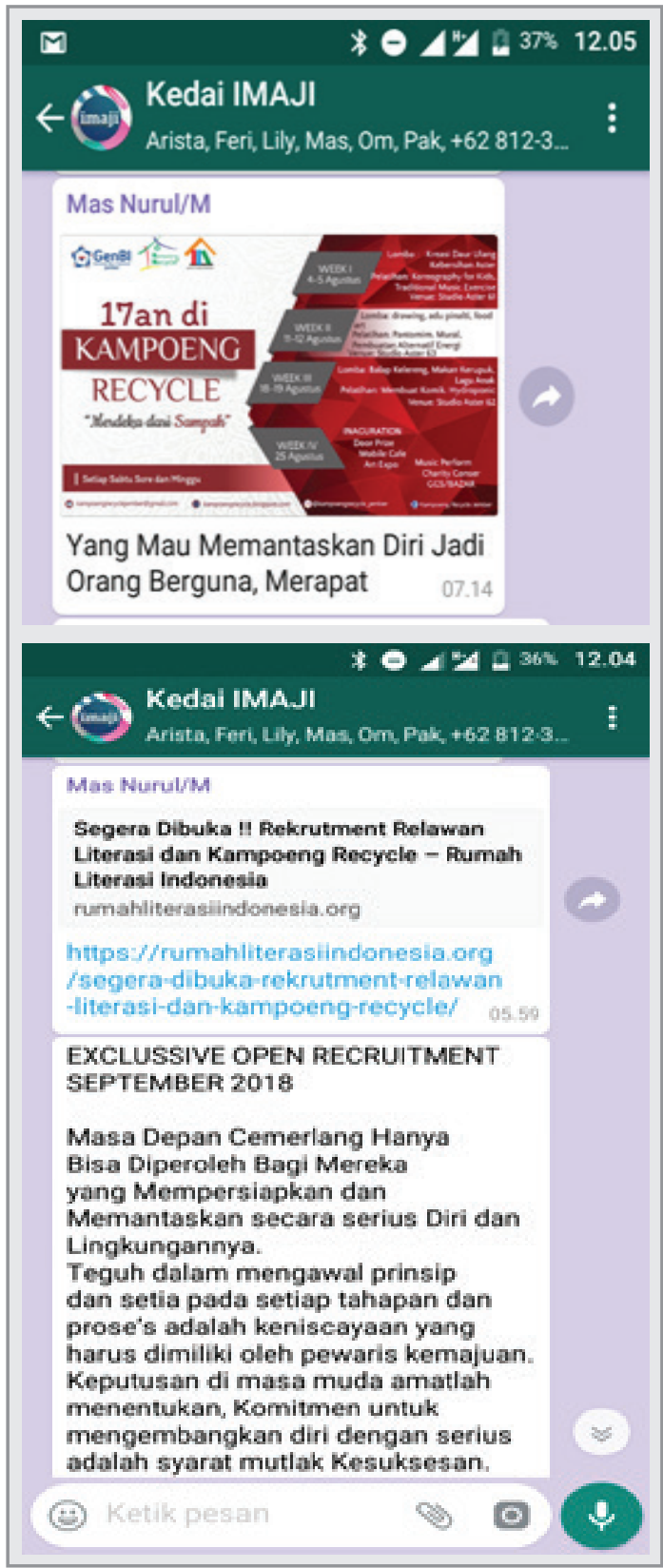

Sumber : Grup whassapp Kedai Imaji 
Tidak hanya menghadirkan perubahan sosial yang cepat, era digital juga mampu kemampuan jaringan untuk membentuk kepribadian. Pengenalan orang atau gerakan berbasis pada jaringan yang dimiliki. Demikian juga dengan Kampoeng Recycle, pengenalan orang terhadap gerakan yang dilakukan oleh pengurus Kampoeng Recycle bukan karena mereka adalah warga RT 6 perumahan Taman Gading Jember, akan tetapi karena mereka melihat dan membaca profil Kampoeng Recycle di media sosial (whatsapp, facebook, instagram).

Melalui grup whatsapp "kedai imaji” penggagas Kampoeng Recycle secara simultan memelihara jaringan dan membentuk "personality" dalam jaringan tersebut. Kepribadian yang nampak adalah kepribadian yang pro lingkungan, kerelawanan dan pemberdayaan untuk pelestarian lingkungan. Oleh karena itu, membangun jaringan dalam dunia virtual menjadi strategi yang sangat jitu dalam menyebarluasakan gagasan Kampoeng Recycle.

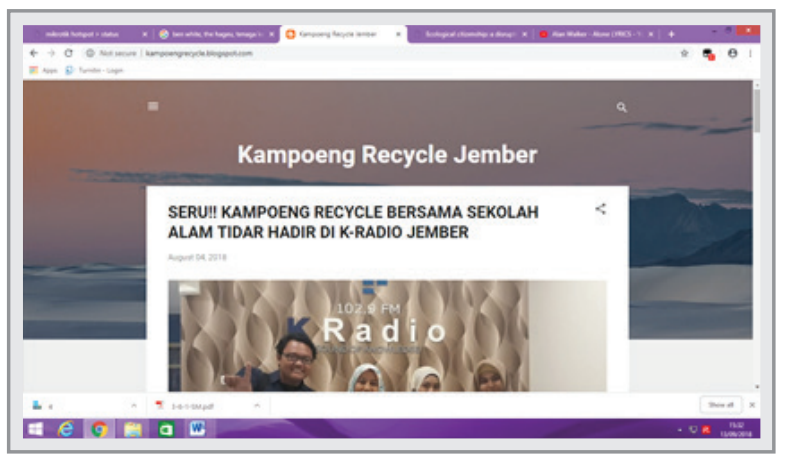

Sumber : kampoengrecycle.blogspot.com

\section{Penyebarluasan Gagasan Melalui Media Internet (Website, Youtube)}

Fakta yang paling penting dalam masyarakat digital adalah fenomena yang terjadi di dunia nyata paralel dengan yang terjadi di dunia virtual. Bahkan (Levin, 2014) menyebutnya sebagai superstruktur yang dibangun oleh manusia menjadi realitas tertinggi. Internet hari ini terkoneksi dengan realitas dan merefleksi realitas itu sendiri. Sebagai sebuah gerakan kesukarelawanan, Kampoeng Recycle menghadapi tantangan yang tidak mudah. Terutama untuk memelihara komitmen gerakan dan bahkan merekrut sukarelawan baru untuk mau berpartisipasi menjaga lingkungan. Dengan kata lain penyebaran gagasan Kampoeng Recycle menjadi strategi penting keberlanjutan gerakan.

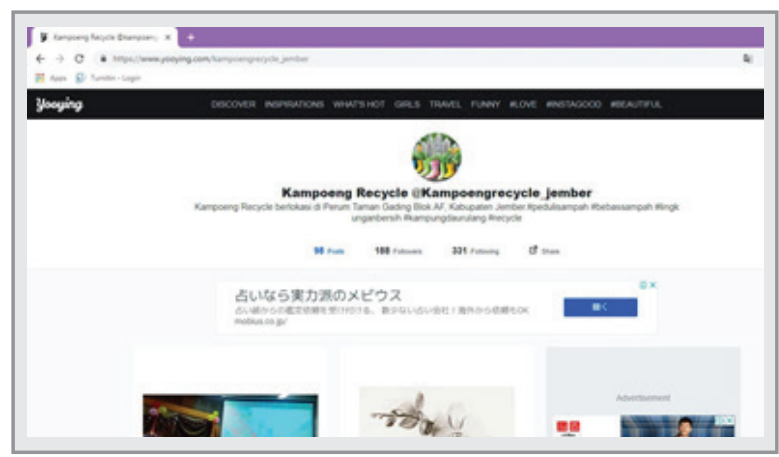

Sumber : www.yooying.com/ksmpoengrecycle jember

Melalui dunia virtual (blog, youtube) keberadaan Kampoeng Recycle banyak diketahui publik. Bermula dari sinilah penyebaran gagasan terjadi. Beberapa relawan yang ingin berpartisipasi dalam Kampoeng Recycle. Keberlimpahan informasi sebagai ciri masyarakat digital telah memberi peluang bagi Kampoeng Recycle untuk dikenal oleh publik.

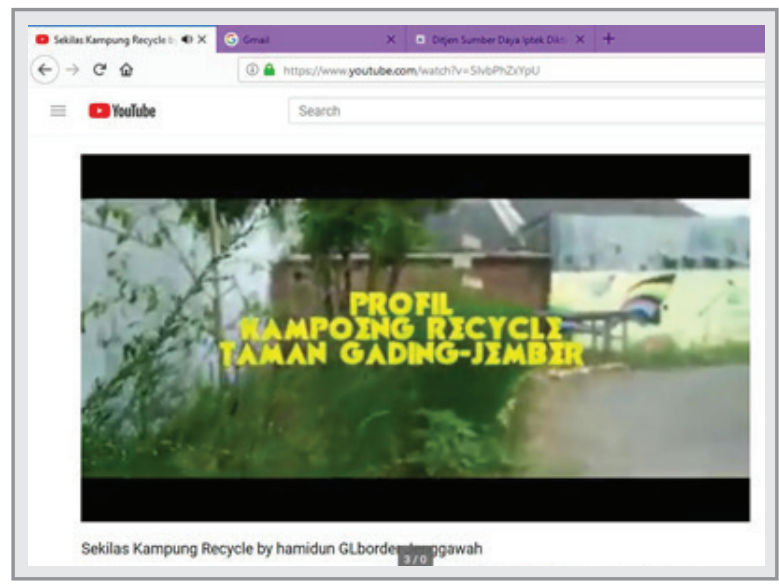

Sumber : www.youtube.com

Dalam konteks ini dunia virtual atau teknologi informasi komunikasi menjadi bagian dari aktivitas pemberdayaan yang dilakukan oleh 
warganegara. Upaya membangun kampung yang bebas sampah dan melestarikan lingkungan dapat terwujud.

\section{KESIMPULAN}

Masyarakat dewasa ini telah berubah sedemikian cepatnya dalam bentuk yang baru. Dimana teknologi digital telah memainkan peran yang sangat penting. Dunia nyata dan dunia virtual menjadi paralel, bahkan dalam beberapa aspek dunia virtual menjadi superstruktur yang merefleksi kenyataan di dunia nyata. Gerakan Kampoeng Recycle terjadi di dunia nyata, namun tidak menjadi nyata jika gerakan ini tidak menggunakan teknologi informasi dan internet untuk menyebarkan gagasannya.

Dalam masyarakat digital yang juga ditandai dengan perkembangan e-commerce yang pesat, pelestarian lingkungan masih menjadi tantangan terbesarnya. Meskipun banyak ahli mengatakan era ini adalah era paperless, namun eksploitasi besar-besaran terhadap alam masih terjadi. Hal ini mau tidak mau menggugah kesadaran warga negara untuk bisa melestarikan ekologinya agar bisa diwariskan kepada generasi selanjutnya. Permasalahan sampah elektronik akibat masyarakat yang semakin konsumtif dan penggunaan energi yang juga semakin boros membuat alam semakin terdegradasi.

Gerakan kewarganegaraan ekologis menjadi konsep yang cukup menjanjikan sebagai konsep gerakan pelestarian lingkungan. Kampoeng Recycle Jember melalui gagasannya mengelola sampah telah mengkampanyekan konsep kewarganegaraan ekologis dengan beberapa strategi. Pertama, mengembangkan trilogi eco structures, eco literacy dan eco-preneurship dalam setiap gerakannya. Kedua, melibatkan generasi muda yang potensial untuk menyebarluaskan gagasan dan meningkatkan partisipasi generasi muda dalam pelestarian lingkungan. Ketiga, penggunaan media sosial untuk menarik relawan-relawan baru agar terlibat dalam gerakan Kampoeng Recycle. Penyebarluasan gagasan melalui media internet. Diharapkan tujuan Kampoeng Recycle sebagai sebuah gerakan pro lingkungan berbasis komunitas dapat menciptakan semakin banyak lagi warga negara yang memiliki wawasan ekologi dan berpartisipasi dalam pelestarian lingkungan.

\section{DAFTAR PUSTAKA}

Agyeman, Julian and Bob Evans. 2005. Justice, Governance, and Sustainability: Perspectives on Environmental Citizenship from North America and Europe. In Environmental Citizenship, ed. A. Dobson and D. Bell, 185-206. Cambridge, MA: MIT Press.

Barry, John. 2006. Resistance is Fertile: From Environmental Sustainability to Citizenship. In Environmental Citizenship, ed. A. Dobson and D. Bell, 21-48.Cambridge, MA: MIT Press.

Bell, Derek R. 2005. Liberal environmental citizenship. Environmental Politics 14(2): 179-194.

Castells, M. 1998. The Information Age: Economy, Society and Culture. Blackwell, Oxford

Carlsson, Monica and Bjarne Bruun Jensen. 2006. Encouraging environmentalcitizenship: The roles and challenges for schools. In Environmental Citizenship,ed. A. Dobson and D. Bell, 237-261. Cambridge, MA: MIT Press.

Curtin, Deane W. 1999. Chinnagounder's Challenge: The Question of Ecological Citizenship. Bloomington: Indiana University Press.

Dobson, Andrew, and Ángel Valencia Sáiz. 2005. Introduction. Environmental Politics 14(2): 157-162.

Dobson, Andrew and Derek Bell. 2006. Introduction. In Environmental Citizenship, ed. A. Dobson and D. Bell, 3-17. Cambridge, MA: MIT Press. 
Eckersley, Robyn. 1996. Greening Liberal Democracy: The Rights Discourse Revisited. In Democracy and Green Political Thought: Sustainability, Rights and Citizenship, ed. B. Doherty and M. de Geus, 212-236. London:Routledge.

Gough, Stephen and William Scott. 2006. Promoting Environmental Citizenship Through Learning: Toward a Theory of Change. In Environmental Citizenship, ed. A. Dobson and D. Bell, 263-285. Cambridge, MA: MIT Press.

Hailwood, Simon. 2005. Environmental citizenship as reasonable citizenship. Environmental Politics 14(2): 195-210.

Hermann, M., Pentek, T., \& Otto, B. (2016). Design Principles for Industrie 4.0 Scenarios. Presented at the 49th Hawaiian International Conference on Systems Science.)

Jelin, Elizabeth. 2000. Towards a global environmental citizenship. CitizenshipStudies 4(1): 47-62.

MacGregor, Sherilyn. 2006. Beyond Mothering Earth: Ecological Citizenship and the Politics of Care. Vancouver: University of British Columbia Press.

Karen Mossberger, Caroline J. Tolbert, and Ramona S. McNeal.(2008). Digital Citizenship. London, England: The MIT Press Cambridge, Massachusetts.

Lupton, Deborah (2013) Introducing digital sociology. Sydney: University of Sydney

Latta, Alex and Garside, Nick. 2005. Perspectives on Ecological Citizenship: An Introduction. Environments a Journal of Interdisciplinary Studies, Volume 33 Number 32005.

Mariyani, 2017. Strategi Pembentukan Kewarganegaraan Ekologis. Prosiding Konferensi Nasional Kewarganegaraan III. p-ISSN 2598-5973. e-ISSN 2599-008X. 11 November 2017, Universitas Ahmad Dahlan, Yogyakarta

Nagra, V, 2010. Environmental Education Awareness among School Teachers. Enviromentalist, 30:153-162)

Prasetiyo, Wibowo Heru dan Dasim Budimansyah, 2016. Warga Negara dan Ekologi : Studi Kasus Pengembangan Warga Negara Peduli Lingkungan Dalam Komunitas Bandung Berkebun. Jurnal Pendidikan Humaniora.
Vol 4 No 4 hal 177-186 Desember 2016.

Sui, Daniel Z. And Rejeski, David W., 2002, Environmental Impacts of the Emerging Digital Economy : The E-For-Environment E-Commerce?. Environmental Management Vol. 29, No. 2, pp. 155-163 (C) 2002 Springer-Verlag New York Inc. DOI: 10.1007/s00267-001-0027-X

Smith, Mark J. 1998. Ecologism: Towards Ecological Citizenship. Minneapolis: University of Minnesota Press.

Smith, Mick. 2005. Citizens, denizens and the res publica: Environmental ethics, structures of feeling and political expression. Environmental Values 14: 145-62.

Tchobanogious, George. Theisen, Hilary. Vigil, Samuel. 1993. Integrated Solid Waste Management. New york: McGraw-Hill.

Yahya, Muhammad. 2018. Era Industri 4.0 Tantangan Dan Peluang Perkembangan Pendidikan Kejuruan Indonesia. Makalah yang disampaikan dalam Pidato Pengukuhan Penerimaan Jabatan Professor Tetap dalam Bidang Ilmu Pendidikan Kejuruan Fakultas Teknik Universitas Negeri Makassar Tanggal 14 Maret 2018.

Valencia Sáiz, Ángel. 2005. Globalisation, cosmopolitanism and ecological citizenship. Environmental Politics 14(2): 163-178.

\section{Sumber Internet}

https://akcdn.detik.net.id/community/media/visual/ 2016/06/29/6b6d8360-ca97-4027-96e9-d28 9a61f123a.jpg?w $=700 \& q=90$ Asia menjadi benua penyumbang sampah elektronik terbesar

https://ekbis.sindonews.com/read/1317290/34/ perusahaan-ekspedisi-berperan-pentingdorong-pertumbuhan-ukm-1530201209

Fatimah Kartini Bohang, 2018. Berapa Jumlah Pengguna Internet Indonesia. Dalam https://tekno.kompas.com/read/2018/02/22/ 16453177/berapa-jumlah-pengguna-internet -indonesia

http://www.listrikindonesia.com/konsumsi energi butuh perubahan paradigma 325.htm

https://radarjember.jawapos.com/read/2017/12/ 27/35837/kampoeng-recycle-ajak-wargamanfaatkan-sampah-sendiri

https://radarjember.jawapos.com/read/2018/04/23/ 
67263/kembangkan-trilogi-kampoeng-recycle http://kampoengrecycle.blogspot.com/2018/08/ mengenal-kampoeng-recycle-jember-what.html https://www.timesindonesia.co.id/read/169916/ 2/20180415/172123/belajar-cara-memanfaat kan-sampah-di-kampoeng-recycle-jember

https://rumahliterasiindonesia.org/lanching-rumahliterasi-jember-rli-gandeng-bank-sampahinisiasi-kampoeng-recycle

https://artikellisawati.blogspot.com/2018/02/ kampoeng-recycle-ajak-warga-manfaatkan. $\underline{\mathrm{html}}$ 